\title{
The Neurobiological Bases of Memory Formation: From Physiological Conditions to Psychopathology
}

\author{
Reto Bisaz Alessio Travaglia Cristina M. Alberini \\ Center for Neural Science, New York University, New York, N.Y., USA
}

\section{Key Words}

Memory - Stress - Molecular mechanisms - Consolidation .

Reconsolidation · Retrieval · Posttraumatic stress disorder

\begin{abstract}
The formation of long-term memories is a function necessary for an adaptive survival. In the last two decades, great progress has been made in the understanding of the biological bases of memory formation. The identification of mechanisms necessary for memory consolidation and reconsolidation, the processes by which the posttraining and postretrieval fragile memory traces become stronger and insensitive to disruption, has indicated new approaches for investigating and treating psychopathologies. In this review, we will discuss some key biological mechanisms found to be critical for memory consolidation and strengthening, the role/s and mechanisms of memory reconsolidation, and how the interference with consolidation and/or reconsolidation can modulate the retention and/or storage of memories that are linked to psychopathologies.

(c) 2014 S. Karger AG, Basel
\end{abstract}

\section{KARGER}

E-Mail karger@karger.com

www.karger.com/psp

\section{Introduction}

Memory, the ability to retain information and recall it at a later time, is a biologically fundamental function essential for survival. Furthermore, memories shape our identity: we are who we are because of our memories, which guide our thoughts and decisions, and influence our emotional reactions.

Memories exist in different forms and rely on distinct neural systems. On the basis of their duration, memories can be classified into short- and long-term. While shortterm memory is the ability to hold and recall information for a short period of time, usually for a few seconds, longterm memories store information for long-lasting periods, sometimes for an entire lifetime. Short- and longterm memories can also be distinguished on the basis of their biological mechanisms: while the former rely on existing networks and posttranslational modifications, the latter is accompanied by structural and functional changes of neural networks that require de novo gene expression [1-6].

Memories can also be classified according to their behavioral manifestation, which reflects the use of distinct 
underlying networks or memory systems. For example, a major distinction is between explicit (e.g. declarative) and implicit (e.g. procedural) memories [7, 8]. Declarative memories are memories that can be consciously recalled such as those of facts, people and events, whereas procedural memories are those that store information about skills, for example driving a car, riding a bike or playing piano. While declarative memories are known to critically engage the medial temporal lobe, and particularly the hippocampus, procedural memories critically recruit the cerebellum. Despite this distinction, memories are often complex and made from experiences that involve multiple memory systems interacting with each other.

In the last two decades, one of the main interests of neuroscientists has been the identification of the biological mechanisms that underlie the formation and storage of memories. Studies in invertebrate systems like Aplysia californica and Drosophila melanogaster have paved the way to the molecular and cellular discoveries in vertebrate and particularly in mammalian systems. Most studies have investigated temporal lobe-dependent memories. From genetic, molecular, electrophysiological and anatomical investigations it has emerged that molecular modifications at all levels, posttranslational, translational and transcriptional, play a critical role in long-term memory formation. These changes include both general mechanisms of long-term plasticity, which occur in many brain regions and with all paradigms involving long-lasting changes, as well as selective mechanisms, which are found in specific brain regions and cell populations [9-12].

One general feature of long-term memory formation across memory systems and species is that a newly encoded memory initially exists in a fragile state and can be disrupted very easily by several types of interferences, from pharmacological to molecular to behavioral. With time, the memory becomes stronger and resilient to disruption. This process of strengthening and stabilization is known as memory consolidation $[2,5,6,13,14]$. Once consolidated, hence insensitive to interferences, memory was believed to be 'fixated' and stored. However, studies that have been particularly revived in the last 15 years have shown that a memory that has become insensitive to molecular interferences can again become labile if it is reactivated, for example by retrievals. This postretrieval fragility, like the one that occurs after acquisition, is temporally limited and the memory returns to a stable state through a process known as reconsolidation [15-18]. Both consolidation and reconsolidation are phases dur- ing which memory is vulnerable to interference and during which a strengthening or weakening of the memory trace can be achieved. This understanding - and more to come - is extremely important for potential clinical applications: in principle, according to the consolidation and reconsolidation mechanisms, it is possible to strengthen weak memories or memories that are easily lost, or conversely weaken memories that are too strong and linked to psychopathologies, like those for example associated with posttraumatic stress disorder (PTSD), anxiety or substance abuse [17, 19-21].

\section{Memory Consolidation}

Memory consolidation initiates with a gene expression-dependent phase that lasts for several hours or days. This process, known as cellular or molecular consolidation $[4,22]$, represents the initial, highly fragile phase of memory storage. However, several types of memories that rely on the hippocampus are not fully processed and stable after this initial phase: although considered consolidated according to molecular interferences, these memories are still undergoing a great deal of processing that culminates with a network rearrangement that is accompanied by a decline in the critical role of the hippocampus. If the hippocampus is inactivated or lesioned during this phase, the memories are lost. This process lasts for weeks in animals and up to years in humans, and it is known as system consolidation $[10,23]$.

We have studied the mechanisms of the consolidation phases by using rats trained in the inhibitory avoidance task (IA). IA is a fear conditioning-based task, in which the animal encounters an aversive experience (foot shock) in a given context, hence learns to avoid it when represented with that context at later times. The advantage of this task is that it is learned in a single trial, thus allowing the identification of rapid changes occurring in the brain after encoding and the follow-up of their progression over time. Focusing first on the dorsal hippocampus, a region required for the formation of contextual associations, we have found that, in this region, the activation of the pathways mediated by the transcription factors cAMP response element-binding protein (CREB) and CCAAT enhancer-binding protein $\beta$ and $\delta(\mathrm{C} / \mathrm{EBP} \beta$ and $\delta)$ is required for IA memory consolidation [5, 24-26]. Several studies, including ours, have led to the conclusion that the CREB-C/EBP is an evolutionarily conserved molecular pathway of long-term plasticity and memory formation, 
as it plays a necessary role in these processes in various learning paradigms and species ranging from invertebrates to mammals $[5,27]$.

The understanding of upstream and downstream mechanisms of the activation of the CREB-C/EBP cascade is important because it offers the identification of targets that can be used to develop strategies for strengthening or weakening memories $[28,29]$. Starting with the upstream regulation of the CREB-C/EBP cascade, as it is well known that stress hormones modulate memory formation and retention, we tested the hypothesis that the learning-dependent activation of the CREB-C/EBP pathway might be regulated by stress.

\section{Stress Mechanisms and Memory Consolidation}

Emotionally charged or salient events are better remembered than emotionally neutral experiences, which in fact are often quickly forgotten. The emotion involved can be either positive (excitement and pleasure) or negative (pain, fear, trauma). Traumatic experiences, chronic stress and painful experiences are linked to the development and progression of psychopathologies like anxiety disorders, depression, PTSD and substance abuse [30-35].

A large number of pharmacological and behavioral studies have shown that the level of stress follows an inverted $U$ relationship with memory retention. Increasing levels of stress are required to form long-lasting memories that are proportionally stronger and more persistent. However, when stress becomes too intense or is chronic, memory can be impaired. Accordingly, it has been found that the levels of the stress hormones noradrenaline and glucocorticoids, which are released in response to stress, mediate and modulate memory retention according to an inverted U-shaped curve [36-38]. Notably, the underlying molecular mechanisms of these effects have remained elusive, until recently.

Recent studies, including those from our laboratory, have investigated the mechanisms activated downstream of glucocorticoid receptors (GRs) and implicated in longterm memory formation. It emerged that after learning GRs regulate several intracellular signaling pathways known to be required for memory consolidation. These include the pathways activated by CREB, mitogen-activated protein kinase, calcium/calmodulin-dependent protein kinase II (CaMKII) and brain-derived neurotrophic factor (BDNF) [39-41]. In addition, GRs control epigenetic modifications that influence long-term memory retention (fig. 1) [42-44].

Memory Formation Mechanisms and Psychopathology
In our studies with rat IA, we found that, in the dorsal hippocampus, GRs control the rapid learning-dependent increase in CREB phosphorylation and the expression of the immediate early gene activity-regulated cytoskeleton-associated protein as well as the increase in synaptic phospho-CaMKIIa, phosphosynapsin-1 and AMPA receptor subunit GluA1 expression. We also found that inhibition of GRs in the rat hippocampus significantly reduces the phosphorylation of the tropomyosin-related kinase B receptor, extracellular-signal-regulated kinase $1 / 2$, protein kinase $B$ and phospholipase $\mathrm{C} \gamma$. Because these pathways are all canonical activation pathways downstream of BDNF, we concluded that the BDNF-dependent pathway is a key downstream effector of GR activation during memory consolidation (fig. 1) [41].

In agreement with this conclusion, we found that intrahippocampal injections of BDNF, but not of other neurotrophins, such as nerve growth factor and neurotrophin 3, rescue both the molecular impairments and the amnesia caused by GR inhibition. The effect is selective for GRs because BDNF does not rescue behavioral deficits caused by the inhibition of $\beta$-adrenergic receptors, underscoring the critical and specific role of the BDNFmediated signaling pathway in the GR-dependent molecular activations required for memory consolidation [41].

Hence, we proposed a model that explains, at least in part, the nature of the biological mechanisms involved in the formation of long-term memories elicited by stressful or arousing experiences: we suggested that evolution has selected mechanisms of growth and prosurvival in response to stress as the fundamental molecular pathways activated by learning and recruited in brain cells to form long-term memories [45].

Although the activation of the GR/BDNF pathway is critical for proper memory consolidation in conditions of stress levels that are within normal ranges (beneficial stress levels), prolonged or extensive stress and abnormal levels of glucocorticoids can negatively regulate the BDNF response and memory processes [46-48]. Various psychiatric disorders that are associated with declarative memory impairments, in particular major depression disorder, have been linked to altered functioning of the hypothalamic-pituitary-adrenal axis [49]. A significant number of depressed patients have increased levels of cortisol in the saliva and plasma, as a result of an increased activity of the pituitary and adrenal glands, due to reduced GR-mediated feedback inhibition by endogenous glucocorticoids, which are thought to be related to func- 


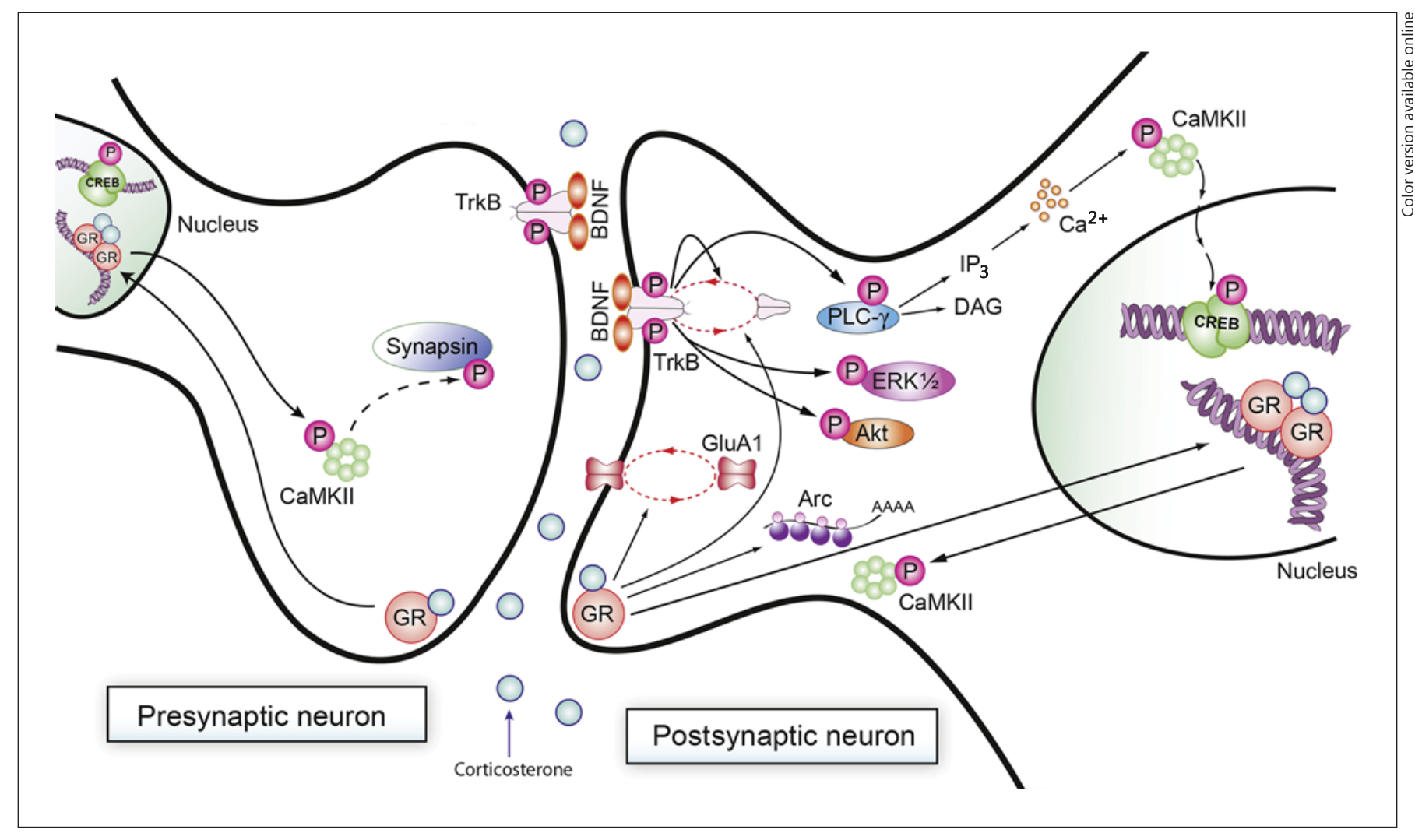

Fig. 1. Schematic representation of learning-induced changes in the hippocampus through the GR-BDNF-tropomyosin-related kinase $B$ receptor (TrkB) pathway. Activated GRs rapidly enhance the translation of activity-regulated cytoskeleton-associated protein and may influence trafficking of TrkB to the membrane surface and/or BDNF release. BDNF binding to its receptor TrkB leads to its phosphorylation, which results in the activation of extracellular-signal-regulated kinase $1 / 2$ (ERK1/2), protein kinase $B$ (Akt) and phospholipase C $\gamma$ (PLC- $\gamma)$. In parallel, activated GRs, via transcription-dependent mechanisms, also rapidly lead to CaMKIIa phosphorylation. The activation of ERK1/2, Akt, PLC- $\gamma$

tional and expression changes in the GR [50]. Indeed, reduced levels of GR have been found post mortem in the brain of depressed suicide patients, and antidepressant treatment not only ameliorates cognitive functions but also increases GR and BDNF expression, as well as GRmediated feedback inhibition in both laboratory animals and humans [51-55].

Thus, our results and working model together with clinical evidence, agree with the idea that the convergence between GR and BDNF pathways may be an important node of dysfunction in stress-related cognitive impairments and affective disorders. and CaMKII $\alpha$ pathways independently or in concert can converge on CREB phosphorylation, which leads to the synthesis of BDNF. The newly synthesized BDNF sustains the activation of the pathways and results in persistent phosphorylation of CREB, CaMKIIa and a downstream presynaptic target of CaMKIIa, phosophosynapsin-1. Thus, GR activation recruits pre- and postsynaptic mechanisms to mediate memory consolidation [41]. Arc = Activity-regulated cytoskeleton-associated protein; GluA1 $=$ AMPA receptor subunit A1; DAG = diacylglycerol; $\mathrm{IP}_{3}=$ inositol triphosphate . Figure adapted from Finsterwald and Alberini [45].

\section{Memory Reconsolidation}

For a long time, memory consolidation was seen as a unitary process that transforms a fragile memory trace into a stable one, once and for all. However, studies done in the 1960s and then re-exploded in the last 15 years have demonstrated that memories that have become insensitive to disruption by certain types of interferences, become again transiently labile if they are recalled. Because the recalled memory must again be stabilized, this postretrieval process has been termed memory reconsolidation $[18,56]$. In the last decade, several questions have been asked about memory reconsolidation. First, is reconsoli- 
dation a mere repetition of the consolidation process? The results of several studies suggest that consolidation is distinct from reconsolidation because it engages distinct brain circuits, hence perhaps mechanisms, although, in the engaged regions, molecular mechanisms of long-term plasticity appear to be common denominators $[13,57]$. Second, does reconsolidation occur every time a memory is recalled and/or a trace is reactivated? The answer to this question is still controversial. With IA, contextual fear conditioning and drug-induced memories, in rodents as well as other types of fear memories in fish, the passage of time is a key limiting factor for the postretrieval vulnerability of memory. In fact, upon reactivation, a young memory is more fragile and easily disrupted than an old one indicating that over time memory becomes increasingly stable and in some cases insensitive to postreactivation interference $[19,58-61]$. In our rat IA paradigm, systemic injection of protein synthesis inhibitors after reactivation produces a decrementally graded amnesia in 2-day- and 1-week-old memories, but when the same treatment is performed on memories 2 and 4 weeks old, the amnestic effect is no longer observed $[25,58]$. However, auditory fear conditioning, a cue association, seems to remain sensitive to disruption following memory reactivation for at least 45 days [62], suggesting that different types of memory have different sensitivities to postreactivation interference $[15,63]$.

A third and important question asked about memory reconsolidation is: what is its function? Why does memory become labile after retrieval or reactivation? Two main hypotheses have been proposed to explain the functional role of reconsolidation. The first suggests that reconsolidation strengthens the memories; in other words, the phase of temporary fragility mediates additional consolidation and therefore produces a stronger and longerlasting memory. The second hypothesis posits that reconsolidation allows the association of new information into memories of past events, in order to integrate new learning with already established and reactivated memories.

We tested both hypotheses with rat IA and found that reconsolidation strengthens memory but does not mediate memory updating, when updating is creating new associations to a reactivated memory. Specifically, we found that the reconsolidation of the original memory takes place independently from the formation of the new association, as the two can be doubly dissociated [64]. We concluded that, although the old memory needs to be retrieved in order to make new associations, its reconsolidation process is not engaged in establishing the link between the new information and the reactivated memory, but

Memory Formation Mechanisms and Psychopathology rather this new association is processed as a new memory [64]. In contrast, several studies argue that reconsolidation is a mechanism of memory updating [65-69]. We only partially agree with this conclusion and propose that reconsolidation updates the memory when the update is adding information to the same trace (e.g. strengthening). However, we disagree with the interpretation that the updating due to adding distinct information (novelty) to a trace is mediated by reconsolidation. The studies arguing in favor of this conclusion do not actually prove that reconsolidation mediates that updating; they show that interference given after the presentation of novel information disrupts the old memory. However, because both consolidation of a new trace and reconsolidation of a reactivated one are sensitive to a similar interference, both processes can be actually disrupted, making the conclusion about a selective role of reconsolidation debatable.

Based on our studies, we speculate that the reconsolidation of medial temporal lobe-dependent memories strengthens or further consolidates the original memory without changing its content [57]. Why is this understanding important? Because it provides critical knowledge for formulating hypotheses about memory processing in both physiological and pathological conditions, as well as designing clinical studies based on the fragility of memory traces.

\section{Consolidation, Reconsolidation and Therapeutic Application}

The studies of the last 20 years show that the process of memory formation and storage is very dynamic and that the storage of information continuously changes through processes of consolidation, reconsolidation and updating. The knowledge of biological mechanisms underlying these processes is important for developing novel specific treatments for mental disorders and cognitive impairments.

For example, for persistent and intrusive memories like those associated with PTSD, it may be possible to target the mechanisms of consolidation and block or reduce the formation or persistence of a very intense memory. Even more easily targeted would be the mechanisms of reconsolidation, as memory retrieval can be controlled. Thus, using a combination of behavioral or psychotherapeutic approaches combined with pharmacology, it might be possible to weaken traumatic memories. Furthermore, the mechanisms of the reconsolidation and consolidation may offer an opportunity to restore the memory with a different emotional valence and intensity. 
Based on the current knowledge of consolidation and reconsolidation, we suggest that an ideal therapeutic approach to psychopathology may be one that modulates only certain components of the memory trace, such as stress, fear and emotions in general, but spares the semantic representation. More studies are needed in models of traumatic memories for understanding whether this is possible.

Using the IA in rats, we have tested whether blocking the mechanisms of stress, and specifically GRs, which mediate and modulate memory consolidation and reconsolidation, reduce fear memory. We reasoned that when a traumatic experience is recalled, a stress response is initiated, which, as shown by our studies described above, activates the cascade of gene expression mediating memory consolidation and strengthening. Thus, we tested whether blocking the action of GRs could prevent reconsolidation and memory strengthening. The GR antagonist mifepristone (RU38486), administered after the recall of IA either directly into the amygdala [63] or systemically [70], significantly weakened the original memory. With systemic administration, we also found that 1 or 2 treatments were sufficient to achieve maximal disruption of the fear memory, and that the effect selectively targeted the recalled memory without interfering with other unrecalled memories [70]. To examine whether the efficacy of treatment changes with the intensity of a traumatic experience, we tested the effects of mifepristone on memories evoked by different foot shock intensities. We found that, while less intense fear memories (low foot shock intensities) could be easily weakened, strongly traumatic memories (high foot shock intensities) were less susceptible to disruption by postreactivation mifepristone treatment. However, these traumatic memories could be weakened by a double mifepristone treatment administered after memory reactivation evoked a week after training [70]. These data suggest that the effect of a reconsolidationbased treatment on traumatic memories is best achieved by a delayed intervention rather than one given immediately after the trauma [70]. However, the intervention should not be delayed after the system consolidation temporal window, as memory would then be more resistant to disruption because it is more consolidated. A recent pilot study in male veterans with PTSD is in agreement with our IA model data, and reports that mifepristone may have a beneficial effect in PTSD remission [71].

A large body of animal and human studies has also examined the effect of glucocorticoids on memory retention, and has indicated that they exert opposite effects in different memory phases and processes, e.g. typically facilitating memory consolidation and reconsolidation pro- cesses, but impairing memory retrieval $[31,38,72,73]$. Since in PTSD traumatic memories are distressing and continuously retrieved, studies have tried to block memory retrieval in patients with PTSD by daily administration of cortisol over a 1-month period [74]. Interestingly, a significant within-subject treatment effect was reported in both the intensity of feeling of reliving the traumatic event as well as the intensity of physiological distress [74]. Moreover, acute cortisol treatments were also successful in enhancing extinction-based psychotherapies in patients with phobias $[75,76]$. In light of all these results, the stress hormone cortisol and its receptors appear to be a promising target for pharmacologic intervention in trauma-related pathologies, including PTSD and phobias.

In the last decade mounting evidence shows that the endocannabinoid system plays an important role in modulating consolidation and reconsolidation of emotionally aversive memories through a combined action of the type 1 cannabinoid receptor (CB1R) and glucocorticoids [7779]. Specifically, it has been hypothesized that stress-induced glucocorticoid release results in a rapid synthesis of endocannabinoids in the amygdala, which in turn suppress GABAergic/inhibitory input of noradrenergic neurons, resulting in an enhancement of noradrenergic activation and thus consolidation of emotionally aversive memories [77, 80]. Notably, injection of rats with the CB1R agonists into the amygdala enhanced the consolidation of conditioned fear, whereas a CB1R antagonist impaired fear memory formation. These effects on fear conditioning are not restricted to the amygdala, but also involve pathways between the amygdala and the medial prefrontal cortex [81-85]. Moreover, activation of CB1R via systemic or intrahippocampal administration of either CB1R agonists or endocannabinoid reuptake blockers has been shown to facilitate fear extinction in rodents and fear extinction memory recall in humans [86-91]. These studies indicate that the endocannabinoid system may represent a key modulator of environmental and stress influences on memory processes and should be explored as a possible therapeutic target for the treatment of neuropsychiatric illness involving memory dysfunctions, including mood and anxiety disorders [92-94].

It is clear that a better knowledge of the consolidation and reconsolidation mechanisms of fear memories is critical for better understanding how to approach fear- and trauma-induced pathologies. However, it is important to keep in mind that it should be understood why only a fraction of people who experience trauma develop PTSD, and why this disorder surfaces over time following trauma. Are the storage mechanisms for recurrent, intrusive 
memories that affect PTSD patients different from the storage mechanisms of traumatic memories in people who do not develop the disorder?

If targeting memory reconsolidation will not be sufficiently efficacious in ameliorating the symptoms of PTSD, an alternative approach would be to target reconsolidation to actually prevent the onset of trauma-induced pathologies. Weakening the intensity of traumatic memories during the first few weeks or months of their consolidation phase may be effective in impeding the development of PTSD or other disorders, including substance abuse, anxiety and depression.

Another interesting approach that targets reconsolidation and is entirely based on behavioral paradigms using a sequential retrieval (reconsolidation) and extinction protocols has been proven effective in both animal models and humans $[95,96]$. Interestingly, extinction after fear memory reactivation leads to a permanent loss of the fear expression, if the extinction is conducted within the reconsolidation's temporal window [95-98]. This approach has recently been successfully applied to reduce craving in drug addicts [99]. Given the high impact of such a therapy in treating several psychopathologies, it would be important to determine its effects in remote pathological memories.

A severe psychiatric disease with alterations of the hippocampus and temporal lobe is schizophrenia, which also exhibits deficits in long-term memory as revealed by verbal learning and memory tests. Schizophrenia is a complex heterogeneous neuropsychiatric disorder, whose core symptoms include, in addition to deficits in declarative long-term memory, distorted perceptions of reality, social avoidance and deficits in executive functions [100102]. The memory deficits are believed to be mainly due to altered brain connectivity in the medial temporal lobe and prefrontal cortex $[102,103]$. Although a dysregulation of the BDNF pathways during brain development has been proposed to mediate these structural alterations, the underlying molecular mechanisms of this dysconnectivity remain largely unknown [104-107].

One important question that recurs in the literature of mood and anxiety disorders is the role of the history of traumatic experiences, particularly those occurring during early development. Compelling evidence from a variety of studies in humans and animals suggests that traumatic experiences during early development predispose individuals to multiple forms of psychopathologies, including depression, PTSD, attention deficit/hyperactivity disorders, schizophrenia and substance abuse [108-114]. Part of the explanation for the enhanced impact of adver- sity in early life is thought to lie in the relatively high degree of plasticity during this period, when environmental factors exert pervasive effects on a number of brain health trajectories [109, 115]. Although considerable progress has been made in understanding the persistent changes in gene regulation via epigenetic mechanisms (specifically those involved in neural systems mediating the response to stress [116-118]), relatively little is known about the neural substrates that mediate memory consolidation processes during early development. Although memories formed during the first few years of life are usually short-lived and become inaccessible after a relatively short time frame [119-122], considerable clinical evidence suggests that young children retain some forms of internal representation of their trauma for months and even years and demonstrate trauma-specific behavioral reenactments, affective responses to traumatic triggers, as well as sensory and somatic symptoms [123-130]. The understanding of the neurobiological mechanisms underlying these pathologies is therefore greatly needed.

\section{Conclusions}

Long-term memory formation is a very dynamic process, which includes several temporal and functional phases, such as encoding, consolidation, retrieval, storage and reconsolidation. Over the past two decades, much progress has been made in understanding the molecular and cellular mechanisms that occur in the brain during these phases, how they evolve over time, in which brain regions they take place, and how they are modulated. This knowledge, in particular for memories associated with fear, stress and trauma, has guided the search for treatments that may alleviate psychopathologies, such as PTSD, anxiety, phobias and addiction. Important parameters including the type of memory, the strength and age of the memory, the type of retrieval, the temporal windows of interference and the type of underlying mechanisms are all critical parameters that should be taken into consideration for successful intervention. Further work is needed to elucidate the biology of memory formation in pathological conditions and early developmental phases.

\section{Acknowledgments}

The work described in this review carried out in Cristina Alberini's laboratory was supported by the National Institute of Mental Health R01 MH065635 and R01 MH074736 and NARSAD to C.M.A. 


\section{References}

$>1$ Kandel ER: The molecular biology of memory $>21$ Hartley CA, Phelps EA: Changing fear: the storage: a dialogue between genes and synapses. Science 2001;294:1030-1038.

2 Dudai Y: The neurobiology of consolidations, or, how stable is the engram? Annu Rev Psychol 2004;55:51-86.

3 Lamprecht R, Farb CR, Rodrigues SM, LeDoux JE: Fear conditioning drives profilin into amygdala dendritic spines. Nat Neurosci 2006;9:481-483.

4 Alberini CM: The role of protein synthesis during the labile phases of memory: revisiting the skepticism. Neurobiol Learn Mem 2008; 89:234-246.

5 Alberini CM: Transcription factors in longterm memory and synaptic plasticity. Physiol Rev 2009;89:121-145.

6 Davis HP, Squire LR: Protein synthesis and memory: a review. Psychol Bull 1984;96:518559.

7 Graf P, Schacter DL: Implicit and explicit memory for new associations in normal and amnesic subjects. J Exp Psychol Learn Mem Cogn 1985;11:501-518.

-8 Squire LR, Zola SM: Structure and function of declarative and nondeclarative memory systems. Proc Natl Acad Sci USA 1996;93. 13515-13522.

$\checkmark 9$ Caroni P, Donato F, Muller D: Structural plasticity upon learning: regulation and functions. Nat Rev Neurosci 2012;13:478-490.

$>10$ Frankland PW, Bontempi B: The organization of recent and remote memories. Nat Rev Neurosci 2005;6:119-130.

11 Dudai Y: The restless engram: consolidations never end. Annu Rev Neurosci 2012;35:227247.

12 Ramamurthi B: The fourth state of consciousness: the thuriya avastha. Psychiatry Cli Neurosci 1995;49:107-110.

13 Dudai Y, Eisenberg M: Rites of passage of the engram: reconsolidation and the lingering consolidation hypothesis. Neuron 2004;44: 93-100.

14 McGaugh JL: Memory - a century of consolidation. Science 2000;287:248-251.

$>15$ Alberini CM, Ledoux JE: Memory reconsolidation. Curr Biol 2013;23:R746-R750.

-16 Nader K, Einarsson EO: Memory reconsolidation: an update. Ann NY Acad Sci 2010; 1191:27-41

-17 Tronson NC, Taylor JR: Molecular mechanisms of memory reconsolidation. Nat Rev Neurosci 2007;8:262-275.

$>18$ Sara SJ: Retrieval and reconsolidation: toward a neurobiology of remembering. Learn Mem 2000;7:73-84.

19 Alberini CM: The role of reconsolidation and the dynamic process of long-term memory formation and storage. Front Behav Neurosci 2011;5:12.

20 Pitman RK: Will reconsolidation blockade offer a novel treatment for posttraumatic stress disorder? Front Behav Neurosci 2011;5:11. neurocircuitry of emotion regulation. Neuropsychopharmacology 2010;35:136-146.

22 Schafe GE, Nader K, Blair HT, LeDoux JE: Memory consolidation of pavlovian fear conditioning: a cellular and molecular perspective. Trends Neurosci 2001;24:540-546.

23 Squire LR, Wixted JT: The cognitive neuroscience of human memory since H.M. Annu Rev Neurosci 2011;34:259-288.

24 Arguello AA, Ye X, Bozdagi O, Pollonini G, Tronel S, Bambah-Mukku D, Huntley GW, Platano D, Alberini CM: CCAAT enhancer binding protein delta plays an essential role in memory consolidation and reconsolidation. J Neurosci 2013;33:3646-3658.

25 Milekic MH, Pollonini G, Alberini CM: Temporal requirement of $\mathrm{C} / \mathrm{EBPbeta}$ in the amygdala following reactivation but not acquisition of inhibitory avoidance. Learn Mem 2007; 14:504-511.

26 Taubenfeld SM, Milekic MH, Monti B, Alberini CM: The consolidation of new but not reactivated memory requires hippocampal C/ EBPbeta. Nat Neurosci 2001;4:813-818.

27 Kandel ER: The molecular biology of memory: CAMP, PKA, CRE, CREB-1, CREB-2, and CPEB. Mol Brain 2012;5:14.

28 Alberini CM, Chen DY: Memory enhancement: consolidation, reconsolidation and insulin-like growth factor 2 . Trends Neurosci 2012;35:274-283.

29 Stern SA, Alberini CM: Mechanisms of memory enhancement. Wiley Interdiscip Rev Syst Biol Med 2013;5:37-53.

30 De Kloet ER, Joels M, Holsboer F: Stress and the brain: from adaptation to disease. Nat Rev Neurosci 2005;6:463-475.

31 De Quervain DJ, Aerni A, Schelling G, Roozendaal B: Glucocorticoids and the regulation of memory in health and disease. Front Neuroendocrinol 2009;30:358-370.

32 Sandi C, Richter-Levin G: From high anxiety trait to depression: a neurocognitive hypothesis. Trends Neurosci 2009;32:312-320.

-33 Pitman RK, Rasmusson AM, Koenen KC, Shin LM, Orr SP, Gilbertson MW, Milad MR, Liberzon I: Biological studies of post-traumatic stress disorder. Nat Rev Neurosci 2012; 13:769-787.

34 McEwen BS, Gianaros PJ: Stress- and allostasis-induced brain plasticity. Annu Rev Med 2011;62:431-445.

35 Koob G, Kreek MJ: Stress, dysregulation of drug reward pathways, and the transition to drug dependence. Am J Psychiatry 2007;164: 1149-1159.

36 Roozendaal B, McGaugh JL: Memory modulation. Behav Neurosci 2011;125:797-824.

37 Okuda S, Roozendaal B, McGaugh JL: Glucocorticoid effects on object recognition memory require training-associated emotional arousal. Proc Natl Acad Sci USA 2004;101: $853-858$.
38 Sandi C, Pinelo-Nava MT: Stress and memory: behavioral effects and neurobiological mechanisms. Neural Plast 2007;2007:78970.

39 Revest JM, Di Blasi F, Kitchener P, RougePont F, Desmedt A, Turiault M, Tronche F, Piazza PV: The MAPK pathway and EGR-1 mediate stress-related behavioral effects of glucocorticoids. Nat Neurosci 2005;8:664672 .

40 Revest JM, Kaouane N, Mondin M, Le Roux A, Rouge-Pont F, Vallee M, Barik J, Tronche F, Desmedt A, Piazza PV: The enhancement of stress-related memory by glucocorticoids depends on synapsin-Ia/Ib. Mol Psychiatry 2010;15:1125, 1140-1151.

-41 Chen DY, Bambah-Mukku D, Pollonini G, Alberini CM: Glucocorticoid receptors recruit the aMKIIalpha-BDNF-CREB pathways to mediate memory consolidation. Nat Neurosci 2012;15:1707-1714.

42 Bilang-Bleuel A, Ulbricht S, Chandramohan Y, De Carli S, Droste SK, Reul JM: Psychological stress increases histone $\mathrm{H} 3$ phosphorylation in adult dentate gyrus granule neurons: involvement in a glucocorticoid receptor-dependent behavioural response. Eur J Neurosci 2005;22:1691-1700.

43 Chandramohan Y, Droste SK, Arthur JS, Reul JM: The forced swimming-induced behavioural immobility response involves histone $\mathrm{H} 3$ phospho-acetylation and c-Fos induction in dentate gyrus granule neurons via activation of the N-methyl-D-aspartate/extracellular signal-regulated kinase/mitogen- and stress-activated kinase signalling pathway. Eur J Neurosci 2008;27:2701-2713.

44 Roozendaal B, Hernandez A, Cabrera SM, Hagewoud R, Malvaez M, Stefanko DP, Haettig J, Wood MA: Membrane-associated glucocorticoid activity is necessary for modulation of long-term memory via chromatin modification. J Neurosci 2010;30:5037-5046.

45 Finsterwald C, Alberini CM: Stress and glucocorticoid receptor-dependent mechanisms in long-term memory: from adaptive responses to psychopathologies. Neurobiol Learn Mem 2014;112:17-29.

46 Allen SJ, Dawbarn D: Clinical relevance of the neurotrophins and their receptors. Clin Sci (Lond) 2006;110:175-191.

47 Duman RS, Heninger GR, Nestler EJ: A molecular and cellular theory of depression. Arch Gen Psychiatry 1997;54:597-606.

48 Duman RS, Monteggia LM: A neurotrophic model for stress-related mood disorders. Biol Psychiatry 2006;59:1116-1127.

49 Pariante CM, Lightman SL: The HPA axis in major depression: classical theories and new developments. Trends Neurosci 2008;31: 464-468.

50 Nemeroff CB, Vale WW: The neurobiology of depression: inroads to treatment and new drug discovery. J Clin Psychiatry 2005; 66(suppl 7):5-13 
51 Chen B, Dowlatshahi D, MacQueen GM, 65 Hupbach A, Gomez R, Nadel L: Episodic Wang JF, Young LT: Increased hippocampal BDNF immunoreactivity in subjects treated with antidepressant medication. Biol Psychiatry 2001;50:260-265.

-52 Dwivedi Y, Rizavi HS, Conley RR, Roberts RC, Tamminga CA, Pandey GN: Altered gene expression of brain-derived neurotrophic factor and receptor tyrosine kinase B in postmortem brain of suicide subjects. Arch Gen Psychiatry 2003;60:804-815.

53 Karege F, Vaudan G, Schwald M, Perroud N, La Harpe R: Neurotrophin levels in postmortem brains of suicide victims and the effects of antemortem diagnosis and psychotropic drugs. Brain Res Mol Brain Res 2005;136:2937.

54 Karege F, Perret G, Bondolfi G, Schwald M, Bertschy G, Aubry JM: Decreased serum brain-derived neurotrophic factor levels in major depressed patients. Psychiatry Res 2002;109:143-148.

-55 Pariante CM: The glucocorticoid receptor: part of the solution or part of the problem? J Psychopharmacol 2006;20:79-84.

56 Nader K, Schafe GE, Le Doux JE: Fear memories require protein synthesis in the amygdala for reconsolidation after retrieval. Nature 2000;406:722-726.

57 Alberini CM: Mechanisms of memory stabilization: are consolidation and reconsolidation similar or distinct processes? Trends Neurosci 2005;28:51-56.

58 Milekic MH, Alberini CM: Temporally graded requirement for protein synthesis following memory reactivation. Neuron 2002;36: 521-525.

59 Suzuki A, Josselyn SA, Frankland PW, Masushige S, Silva AJ, Kida S: Memory reconsolidation and extinction have distinct temporal and biochemical signatures. J Neurosci 2004 24:4787-4795.

60 Frankland PW, Ding HK, Takahashi E, Suzuki A, Kida S, Silva AJ: Stability of recent and remote contextual fear memory. Learn Mem 2006; 13:451-457.

61 Graff J, Joseph NF, Horn ME, Samiei A, Meng J, Seo J, Rei D, Bero AW, Phan TX, Wagner F, Holson E, Xu J, Sun J, Neve RL, Mach RH, Haggarty SJ, Tsai LH: Epigenetic priming of memory updating during reconsolidation to attenuate remote fear memories. Cell 2014 156:261-276

62 Debiec J, LeDoux JE, Nader K: Cellular and systems reconsolidation in the hippocampus. Neuron 2002;36:527-538.

63 Alberini CM, Johnson SA, Ye X: Mechanisms and functions of memory reconsolidation; in Alberini CM (ed): Memory Reconsolidation. San Diego, Academic Press, 2013, vol 1, pp 81-117.

64 Tronel S, Milekic MH, Alberini CM: Linking new information to a reactivated memory requires consolidation and not reconsolidation mechanisms. PLoS Biol 2005;3:e293. memory reconsolidation: updating or source confusion? Memory 2009; 17:502-510.

66 Hupbach A, Hardt O, Gomez R, Nadel L: The dynamics of memory: context-dependent updating. Learn Mem 2008;15:574-579.

67 Morris RG, Inglis J, Ainge JA, Olverman HJ, Tulloch J, Dudai Y, Kelly PA: Memory reconsolidation: sensitivity of spatial memory to in hibition of protein synthesis in dorsal hippocampus during encoding and retrieval. Neuron 2006;50:479-489. nado H: Human reconsolidation does not always occur when a memory is retrieved: the relevance of the reminder structure. Neurobiol Learn Mem 2009;91:50-57.

69 Forcato C, Rodriguez ML, Pedreira ME, Maldonado H: Reconsolidation in humans opens up declarative memory to the entrance of new information. Neurobiol Learn Mem 2010;93: 77-84.

70 Taubenfeld SM, Riceberg JS, New AS, Alberini CM: Preclinical assessment for selectively disrupting a traumatic memory via postretrieval inhibition of glucocorticoid receptors. Biol Psychiatry 2009;65:249-257.

71 Golier JA, Caramanica K, Demaria R, Yehuda R: A pilot study of mifepristone in combatrelated PTSD. Depress Res Treat 2012;2012: 393251.

72 De Quervain DJ, Henke K, Aerni A, Treyer V, McGaugh JL, Berthold T, Nitsch RM, Buck A, Roozendaal B, Hock C: Glucocorticoid-induced impairment of declarative memory retrieval is associated with reduced blood flow in the medial temporal lobe. Eur J Neurosc 2003;17:1296-1302.

73 Sandi C: Glucocorticoids act on glutamatergic pathways to affect memory processes. Trends Neurosci 2011;34:165-176

74 Aerni A, Traber R, Hock C, Roozendaal B, Schelling G, Papassotiropoulos A, Nitsch RM, Schnyder U, de Quervain DJ: Low-dose cortisol for symptoms of posttraumatic stress disorder. Am J Psychiatry 2004;161:1488-1490.

75 Soravia LM, Heinrichs M, Aerni A, Maroni C, Schelling G, Ehlert U, Roozendaal B, de Quervain DJ: Glucocorticoids reduce phobic fear in humans. Proc Natl Acad Sci USA 2006;103: $5585-5590$

76 De Quervain DJ, Bentz D, Michael T, Bolt OC, Wiederhold BK, Margraf J, Wilhelm FH: Glucocorticoids enhance extinction-based psychotherapy. Proc Natl Acad Sci USA 2011; 108:6621-6625

77 Hill MN, McEwen BS: Involvement of the endocannabinoid system in the neurobehavioural effects of stress and glucocorticoids. Prog Neuropsychopharmacol Biol Psychiatry 2010;34:791-797.

78 Hill MN, Patel S, Campolongo P, Tasker JG, Wotjak CT, Bains JS: Functional interactions between stress and the endocannabinoid system: from synaptic signaling to behavioral output. J Neurosci 2010;30:14980-14986.
68 Forcato C, Argibay PF, Pedreira ME, Maldo-
79 Steiner MA, Wotjak CT: Role of the endocannabinoid system in regulation of the hypothalamic-pituitary-adrenocortical axis. Prog Brain Res 2008;170:397-432.

80 Morena M, Campolongo P: The endocannabinoid system: an emotional buffer in the modulation of memory function. Neurobiol Learn Mem 2014;112:30-43.

81 Lin HC, Mao SC, Gean PW: Effects of intraamygdala infusion of CB1 receptor agonists on the reconsolidation of fear-potentiated startle. Learn Mem 2006;13:316-321.

82 Campolongo P, Roozendaal B, Trezza V, Hauer D, Schelling G, McGaugh JL, Cuomo $\mathrm{V}$ : Endocannabinoids in the rat basolateral amygdala enhance memory consolidation and enable glucocorticoid modulation of memory. Proc Natl Acad Sci USA 2009;106: 4888-4893.

83 Laviolette SR, Grace AA: Cannabinoids potentiate emotional learning plasticity in neurons of the medial prefrontal cortex through basolateral amygdala inputs. J Neurosci 2006; 26:6458-6468.

-84 Tan H, Lauzon NM, Bishop SF, Bechard MA Laviolette SR: Integrated cannabinoid CB1 receptor transmission within the amygdalaprefrontal cortical pathway modulates neuronal plasticity and emotional memory encoding. Cereb Cortex 2010;20:1486-1496.

-85 Tan H, Lauzon NM, Bishop SF, Chi N, Bechard M, Laviolette SR: Cannabinoid transmission in the basolateral amygdala modulates fear memory formation via functional inputs to the prelimbic cortex. J Neurosci 2011;31:5300-5312.

86 Pamplona FA, Bitencourt RM, Takahashi RN: Short- and long-term effects of cannabinoids on the extinction of contextual fear memory in rats. Neurobiol Learn Mem 2008;90:290293

87 Pamplona FA, Prediger RD, Pandolfo P, Takahashi RN: The cannabinoid receptor agonist WIN 55212-2 facilitates the extinction of contextual fear memory and spatial memory in rats. Psychopharmacology (Berl) 2006; 188:641-649.

88 Chhatwal JP, Davis M, Maguschak KA, Ressler KJ: Enhancing cannabinoid neurotransmission augments the extinction of conditioned fear. Neuropsychopharmacology 2005;30:516-524

89 Izquierdo A, Wellman CL, Holmes A: Brief uncontrollable stress causes dendritic retraction in infralimbic cortex and resistance to fear extinction in mice. J Neurosci 2006;26: 5733-5738.

90 Rabinak CA, Angstadt M, Sripada CS, Abelson JL, Liberzon I, Milad MR, Phan KL: Cannabinoid facilitation of fear extinction memory recall in humans. Neuropharmacology 2013;64:396-402.
Memory Formation Mechanisms and Psychopathology
Psychopathology 2014;47:347-356 DOI: $10.1159 / 000363702$ 
-91 Izquierdo I, Quillfeldt JA, Zanatta MS, Quevedo J, Schaeffer E, Schmitz PK, Medina JH: Sequential role of hippocampus and amygdala, entorhinal cortex and parietal cortex in formation and retrieval of memory for inhibitory avoidance in rats. Eur J Neurosci 1997;9:786-793.

$\$ 2$ Lutz B: The endocannabinoid system and extinction learning. Mol Neurobiol 2007;36: 92-101.

93 Hill MN, Gorzalka BB: The endocannabinoid system and the treatment of mood and anxiety disorders. CNS Neurol Disord Drug Targets 2009;8:451-458.

94 Trezza V, Campolongo P: The endocannabinoid system as a possible target to treat both the cognitive and emotional features of post-traumatic stress disorder (PTSD). Front Behav Neurosci 2013;7:100.

$\checkmark 95$ Monfils MH, Cowansage KK, Klann E, LeDoux JE: Extinction-reconsolidation boundaries: key to persistent attenuation of fear memories. Science 2009;324:951-955.

96 Schiller D, Monfils MH, Raio CM, Johnson DC, Ledoux JE, Phelps EA: Preventing the return of fear in humans using reconsolidation update mechanisms. Nature 2010;463: 49-53.

97 Jones CE, Monfils MH: Using reconsolidation and extinction to weaken fear memories in animal models; in Alberini CM (ed): Memory Reconsolidation. San Diego, Academic Press, 2013, vol 1, pp 165-184.

$\$ 98$ Phelps EA, Schiller D: Reconsolidation in humans; in Alberini CM (ed): Memory Reconsolidation. San Diego, Academic Press, 2013, vol 1, pp 185-212.

99 Xue YX, Luo YX, Wu P, Shi HS, Xue LF, Chen C, Zhu WL, Ding ZB, Bao YP, Shi J, Epstein DH, Shaham Y, Lu L: A memory retrieval-extinction procedure to prevent drug craving and relapse. Science 2012;336:241245.

100 Van Oostrom I, Dollfus S, Brazo P, Abadie P, Halbecq I, Thery S, Marie RM: Verbal learning and memory in schizophrenic and Parkinson's disease patients. Psychiatry Res 2003;117:25-34

101 Cirillo MA, Seidman LJ: Verbal declarative memory dysfunction in schizophrenia: from clinical assessment to genetics and brain mechanisms. Neuropsychol Rev 2003;13: 43-77.

102 Toulopoulouand T, Murray RM: Verbal memory deficit in patients with schizophrenia: an important future target for treatment. Expert Rev Neurother 2004;4:43-52.

103 Stephan KE, Baldeweg T, Friston KJ: Synaptic plasticity and dysconnection in schizophrenia. Biol Psychiatry 2006;59:929-939.
104 Favalli G, Li J, Belmonte-de-Abreu P, Wong $\mathrm{AH}$, Daskalakis ZJ: The role of BDNF in the pathophysiology and treatment of schizophrenia. J Psychiatr Res 2012;46:1-11.

105 Angelucci F, Brene S, Mathe AA: BDNF in schizophrenia, depression and corresponding animal models. Mol Psychiatry 2005;10: 345-352.

106 Muglia P, Vicente AM, Verga M, King N, Macciardi F, Kennedy JL: Association between the BDNF gene and schizophrenia. Mol Psychiatry 2003;8:146-147.

107 Autry AE, Monteggia LM: Brain-derived neurotrophic factor and neuropsychiatric disorders. Pharmacol Rev 2012;64:238-258.

108 Vythilingam M, Heim C, Newport J, Miller $\mathrm{AH}$, Anderson E, Bronen R, Brummer M, Staib L, Vermetten E, Charney DS, Nemeroff CB, Bremner JD: Childhood trauma associated with smaller hippocampal volume in women with major depression. Am J Psychiatry 2002;159:2072-2080.

109 Hackman DA, Farah MJ, Meaney MJ: Socioeconomic status and the brain: mechanistic insights from human and animal research. Nat Rev Neurosci 2010;11:651-659.

110 Pratchett LC, Yehuda R: Foundations of posttraumatic stress disorder: does early life trauma lead to adult posttraumatic stress disorder? Dev Psychopathol 2011;23:477491.

111 Fergusson DM, Lynskey M, Horwood LJ: The adolescent outcomes of adoption: a 16year longitudinal study. J Child Psychol Psychiatry Allied Disc 1995;36:597-615.

-112 Beckett C, Maughan B, Rutter M, Castle J, Colvert E, Groothues C, Kreppner J, Stevens S, O'Connor TG, Sonuga-Barke EJ: Do the effects of early severe deprivation on cognition persist into early adolescence? Findings from the English and Romanian Adoptees Study. Child Dev 2006;77:696-711.

113 Sanchez MM, Ladd CO, Plotsky PM: Early adverse experience as a developmental risk factor for later psychopathology: evidence from rodent and primate models. Dev Psychopathol 2001;13:419-449.

114 Heim C, Plotsky PM, Nemeroff CB: Importance of studying the contributions of early adverse experience to neurobiological findings in depression. Neuropsychopharmacology 2004;29:641-648.

-115 Hanson M, Godfrey KM, Lillycrop KA, Burdge GC, Gluckman PD: Developmental plasticity and developmental origins of noncommunicable disease: theoretical considerations and epigenetic mechanisms. Prog Biophys Mol Biol 2011;106:272-280.
116 Zhang TY, Labonte B, Wen XL, Turecki G, Meaney MJ: Epigenetic mechanisms for the early environmental regulation of hippocampal glucocorticoid receptor gene expression in rodents and humans. Neuropsychopharmacology 2013;38:111-123.

117 Szyf M, Weaver IC, Champagne FA, Diorio J, Meaney MJ: Maternal programming of steroid receptor expression and phenotype through DNA methylation in the rat. Front Neuroendocrinol 2005;26:139-162.

118 Champagne FA, Curley JP: Epigenetic mechanisms mediating the long-term effects of maternal care on development. Neurosci Biobehav Rev 2009:33:593-600.

119 Freud S: Three essays on the theory of sexuality; in Strachey TJ (ed): The Standard Edition of the Complete Psychological Works of Sigmund Freud. London, Hogarth Press, 1953, vol 7.

120 Campbell BA, Spear NE: Ontogeny of memory. Psychol Rev 1972;79:215-236.

121 Spear NE, Parsons P: Analysis of a Reactivation Treatment: Ontogenic Determinants of Alleviated Forgetting. Hillsdale, Erlbaum Associates, 1976.

122 Hayne H: Infant memory development: implications for childhood amnesia. Dev Rev 2004;24:33-73.

123 Terr L: What happens to early memories of trauma? A study of twenty children under age five at the time of documented traumatic events. J Am Acad Child Adolesc Psychiatry 1988;27:96-104.

124 Gaensbauer TJ: Trauma in the preverbal period. Symptoms, memories, and developmental impact. Psychoanal Study Child 1995; 50:122-149.

125 Gaensbauer TJ, Jordan L: Psychoanalytic perspectives on early trauma: interviews with thirty analysts who treated an adult victim of a circumscribed trauma in early childhood. J Am Psychoanal Assoc 2009;57:947977.

126 Peterson C, Rideout R: Memory for medical emergencies experienced by 1- and 2-yearolds. Dev Psychol 1998;34:1059-1072.

127 Paley J, Alpert J: Memory of infant trauma. Psychoanal Psychol 2003;20:329-347.

128 Scheeringa M, Gaensbauer T: Posttraumatic stress disorder; in Zeaanah C (ed): Handbook of Infant Mental Health, ed 2. New York, Guilford Press, 1999, pp 369-381.

129 Terr LC: 'Wild child': how three principles of healing organized 12 years of psychotherapy. J Am Acad Child Adolesc Psychiatry 2003;42:1401-1409.

130 Terr LC: Childhood traumas: an outline and overview. Am J Psychiatry 1991;148:10-20. 